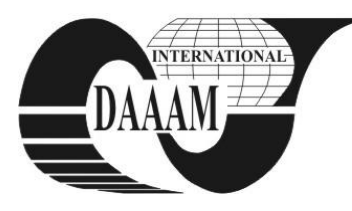

Annals of DAAAM for 2011 \& Proceedings of the 22nd International DAAAM Symposium, Volume 22, No. 1, ISSN 1726-9679 ISBN 978-3-901509-83-4, Editor B. Katalinic, Published by DAAAM International, Vienna, Austria, EU, 2011 Make Harmony between Technology and Nature, and Your Mind will Fly Free as a Bird Annals \& Proceedings of DAAAM International 2011

\title{
PREPARATION OF METALLIC-CERAMIC COMPACT BY TRANSITION TROUGH THE SEMI-SOLID STATE
}

\author{
ELIASOVA, I[vana]; JIRKOVA, H[ana]; KUSY, M[artin]; MASEK, B[ohuslav] \& SVOBODA, J[iri]
}

\begin{abstract}
Components with complex shapes and new types of can be prepared by combining new technologies and different kinds of materials. One of these possibilities is combining powder metallurgy with semi-solid state technology. Different types of composites can be prepared using this technology. The manufacturing process of the composite was tested; its matrix was composed of iron and aluminium, reinforced by alumina particles and by aluminides.

Key words: metal-ceramic composite, rapid solidification, semi-solid state, powder metallurgy
\end{abstract}

\section{INTRODUCTION}

Some components for electronics, aviation, the chemical industry and medicine require very small sizes and difficult shapes and special physical or mechanical properties. These components are usually produced using complex processes and special materials. One suitable method could be the combination of powder metallurgy and unique forming technology in the semi-solid state.

Powder processing in the semi-solid state enables reactions in the powder and its compaction using low forming forces. Complex shapes are achievable in one process (Masek et.al., 2010). It is possible to produce small parts with special properties (mechanical or physical) by combining minithixoforming and powder metallurgy.

Compaction of mechanically compressed powder in the semi-solid state was carried out in the experimental programme. This process is the first step towards the earliest possible application of the gained knowledge for processing these composites using minithixoforming.

\subsection{Thixoforming}

The principle of minithixoforming is the forming of a semiproduct which is, after heating to the processing temperature, partially in liquid and partially in solid state (Atkinson et al., 2010, Omar et al, 2010). This technology enables forming parts with complicated and complex shapes. The ratio of the solid phase should be from $40 \%$ to $60 \%$ after heating to the semi-solid state (Omar et al., 2010, Aišman et al., 2010). The material usually exhibits thixotropic behaviour in this state. Thus, it has high viscosity in quiescent state, but viscosity rapidly decreases with shear stress (Mašek et al., 2010).

A process called 'minithixoforming' for the production of small parts in the semi-solid state was developed in FORTECH. This process is based on lateral extrusion of material.

Using this technology it is possible to form materials which are unformable under different conditions. Furthermore, this technology requires much lower forming forces in comparison with conventional forming technology because materials in the semi-solid state exhibit low deformation resistance. A disadvantage of this process is the need for precise control of the process parameters, particularly of temperature and temperature fields in the semiproduct. It is necessary to ensure this control especially for materials with a narrow interval between solidus and liquidus and for materials which require a precise process temperature for the formation of the desired structure.

The semiproduct was heated using high-frequency resistance heating (Mašek et al., 2010) directly in the die cavity. Therefore, no manipulation of the semiproduct in the semi-solid state was necessary and forming was carried out at a precisely defined temperature. The die was made of titanium alloy and divided into several parts for easier handling of the semiproduct. Pads creating the final shape of the die cavity were inserted into the bottom part of the die (Aišman et al., 2010).

\section{EXPERIMENTAL PROGRAMME}

The experimental programme focused on preliminary tests in which the advantages of powder metallurgy were combined with deformation in the semi-solid state. The goal of the experiment was to obtain a metallic-ceramic compact without visible macroscopic defects during a short processing time, with homogenous distribution of the structure.

The experimental programme focused on testing the exposure of mechanically compacted powder deposited into the container at different temperatures within the semi-solid state. The resulting metallic-ceramic compact was analysed using different metallographic methods; phase fractions were measured using XRD analysis. Local chemical composition was analysed using EDX analysis.

\subsection{Preparation of the Container with Powder Semiproduct}

It was necessary to deposit the powder into the metal container before processing (Fig. 1). The containers had a diameter of $6 \mathrm{~mm}$, wall thickness of $0.58 \mathrm{~mm}$ and length $44 \mathrm{~mm}$ and were made of DIN 1.1013 steel. The initial powder was prepared by mechanical alloying and consisted of $\mathrm{Fe}, \mathrm{Al}, \mathrm{Al}_{2} \mathrm{O}_{3}$ in weight ratios of individual components 93:9.2:10. Milling was performed in a closed box filled with air. This achieved an increased proportion of $\mathrm{Al}_{2} \mathrm{O}_{3}$ at the expense of $\mathrm{Al}$ in the milling process.

Compaction of the powder into the steel container was carried out in several steps (Fig. 1).

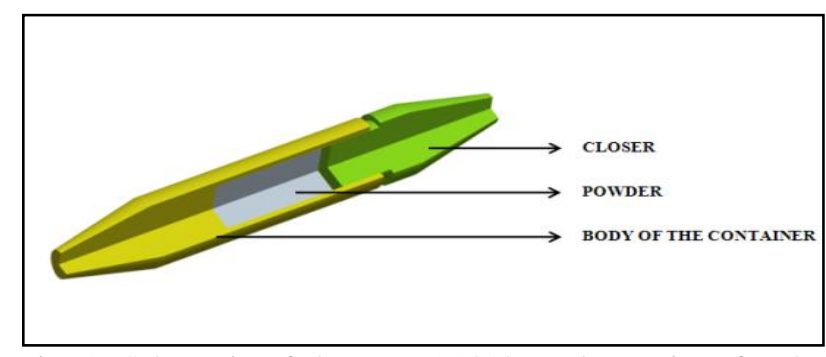

Fig. 1. Schematic of the DIN 1.1013 steel container for the powder 


\subsection{Semi-solid Processing}

The initial experiment was carried out without the die: it served to obtain a homogeneous thermal field in the container during the heating to a temperature between solidus and liquidus. The thermal field on the surface of the container was monitored using a thermovision camera. The thermovision data record revealed that heating the material ensured sufficient homogeneity of the temperature on the surface across the entire working section of the container.

The goal was to find the relationship between the temperature and the structure developed in the composite. Three processing temperatures were tested: 1300, 1400 and $1500^{\circ} \mathrm{C}$.

The first heating temperature was $1300^{\circ} \mathrm{C}$. The analysis showed that during heating to this temperature the powder mixture was not fused.

Therefore, the temperature was increased to $1400^{\circ} \mathrm{C}$ with a 10 s hold at this temperature. Heating of the sample and the following compression deformation with a force of $7 \mathrm{kN}$ were performed in the cavity die. After cutting the container it was detected that the resulting structure consisted of metallicceramic compact without visible macroscopic defects. Microscopic analysis showed discontinuities of a few micrometers at the contact surfaces of several grains. At the same time it was detected that the walls of the container were not connected to the powder.

The temperature was increased for further experiments to $1500^{\circ} \mathrm{C}$ with 10 s hold, to obtain a homogeneous distribution of the structure and for better compaction of the material without the appearance of inhomogenities. Compression deformation force was increased to $10 \mathrm{kN}$. The container was completely compressed by $7 \mathrm{~mm}$ (Fig. 3). The structure in the longitudinal section was formed of metallic-ceramic compact (Fig. 4). Metallographic analysis of the resulting structures was performed using scanning electron microscopy (Fig. 4) and confocal microscopy (Fig. 5). More even distribution of particles was detected near the edge of the compact (Fig. 5b), the homogeneity of the dispersion was lower in the direction towards the centre of the compact.

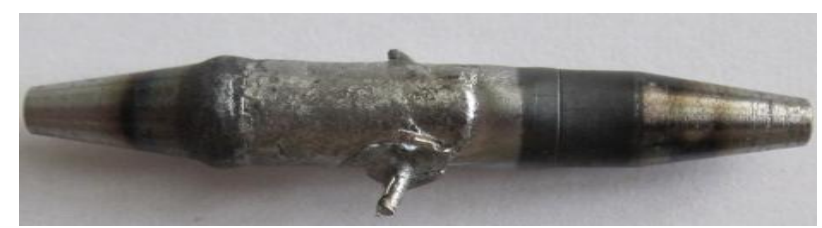

Fig. 2. Container after thermomechanical exposure at $1500^{\circ} \mathrm{C}$, middle melted section with rest of welded thermocouple on the surface

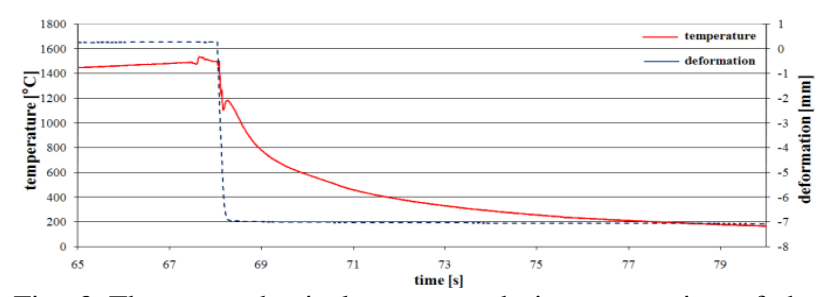

Fig. 3 Thermomechanical exposure during processing of the container in the form

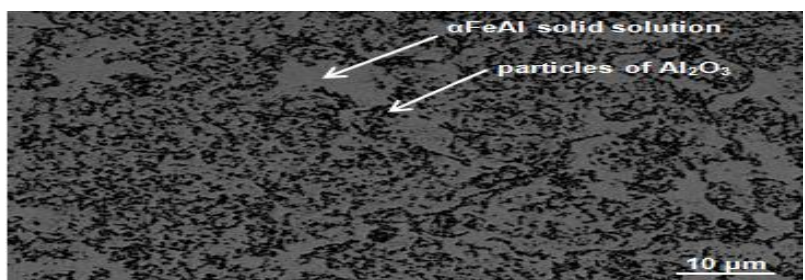

Fig. 4. State of structure after thermomechanical exposure at $1500^{\circ} \mathrm{C}$ with 10 s hold



a)

b)

Fig. 5. Character of structure in longitudinal section after to exposure to $1500^{\circ} \mathrm{C}$

Microstructure consists of particles of $\mathrm{Al}_{2} \mathrm{O}_{3}$ dispersed in the matrix. The composition of the matrix was measured by EDX analysis (Fig. 5). It is assumed on the basis of local chemical analysis that the matrix is composed of Fe based solid solution with up to 20 at.\% of $\mathrm{Al}$ with bcc type lattice structure (Fig. 5).

\section{CONCLUSION}

By interaction of temperature and pressure deformation during processing in the semi-solid state a metallic-ceramic compact $\mathrm{Fe}-\mathrm{Al}-\mathrm{Al}_{2} \mathrm{O}_{3}$ was created without any obvious microscopic or macroscopic defects in one process step. From the results of the EDX analysis it can be assumed that the resulting structure is composed of $\mathrm{Al}_{2} \mathrm{O}_{3}$ particles, which are dispersed in a matrix, consisting of a solid solution of $\mathrm{Fe}$ with the volume of $\mathrm{Al}$ up to 20 at.\% with a crystal lattice of the bcc type.

\section{ACKNOWLEDGEMENT}

This paper includes results created within the projects 1M06032 Research Centre of Forming Technology, VEGA 1/0011/10 and SGS-2011-056 New Unconventional Materials Based on Iron and Vanadium Obtained by Rapid Solidification from Semi-solid State. The projects are subsidised from specific resources of the state budget for research and development.

\section{REFERENCES}

Mašek, B.; Jirková, H.; Aišman, D.; Hronek, P. (2010). Thixoforming von Stahl-ein bisher unerforschtes Verfahren mit einem großen Potenzial, Proceedings of XXIX. Verformungshundlisches Kolloquium, 28.2.-2.3. 2010, Planneralm, ISBN 978-3-902078-148, Buchmayer, B. (Ed.), pp. 13-17, Lehrstuhl für Umformtechnik, Leoben

Atkinson, H.; Rassili, A. (2010). Thixoforming steel, Chapter 1 - Introduction to Thixoforming Steel, Shaker Verlag, ISBN 978-3-8322-9133-4, Aachen

Omar, M.Z. et al. (2009). Solid-liquid structural break-up in M2 tool steel for semi-solid metal processing. Journal of Material Science, Vol. 44, No. 3, (September 2008) 869874, ISSN 0022-2461

Aišman, D. et al. (2010). Metastable structure of austenite base obtained by rapid solidification in a semi-solid state. Journal of Alloys and Compound, Vol. 509, No. 1, (July 2010) 312-315, ISSN 0925-8388

Mašek, B. et al. (2010). Structure of miniature components from steel produces by forming in semi-solid state. Trans. Nonferrous Metal. Soc. China, Vol. 20, No.3, (May 2010) 1037-1041, ISSN 1003-6326 